\title{
Effectiveness and cost-effectiveness of single bolus treatment with abciximab (Reo Pro) in preventing restenosis following percutaneous transluminal coronary angioplasty in high risk patients
}

\author{
Mike Aristides, Michael Gliksman, Narayan Rajan, Peter Davey
}

\begin{abstract}
Objective-To assess the clinical effectiveness and cost effectiveness of abciximab in preventing restenosis after percutaneous transluminal coronary angioplasty (PTCA).
\end{abstract}

Design-Data from a previous study, the EPIC trial, were used because only this trial was able to provide event data capable of constructing a cost effectiveness analysis over six months. All other study data reviewed supported the findings of the EPIC trial. To provide indicative results on long term health outcomes, survival and event-free survival were extrapolated using US epidemiological data in a Markov modelling process.

Setting and patients-Patients who were at high risk for ischaemic complications after PTCA, treated in the standard manner.

Interventions-Abciximab was added to the regimen of intravenous heparin and aspirin.

Results-The EPIC study (n = 2099) indicated an $8.1 \%$ absolute reduction in serious cardiovascular events $(95 \%$ confidence interval $3.1 \%$ to $12.7 \%$ ) and a $23 \%$ relative risk reduction $(p=0.001)$. Based on the six month trial period, the additional cost per patient free from a serious event (Australian dollars) is $\$ 13012$ and for a special risk/benefit measure of outcome, the additional cost is \$14 243. Epidemiological data support extended survival and ischaemic event-free survival with clinically successful PTCA. The results of the modelled analysis indicate a cost per additional life-year gained of $\$ 5547$ and a cost per additional year eventfree of $\$ 4285$.

Conclusions-At up to six months abciximab offers improvements in clinically important outcomes. A modelling exercise explores and highlights the likelihood of significant long term health benefits. The analysis provides information for decision makers and funders to consider the value for money of abciximab. (Heart 1998;79:12-17)

Keywords: abciximab; percutaneous transluminal coronary angioplasty; cost-effectiveness analysis
Percutaneous transluminal coronary angioplasty (PTCA) is generally regarded as a less expensive and less resource intensive alternative to coronary artery bypass grafting (CABG). However, the value of PTCA has been restricted by ischaemic complications occurring as either abrupt closure (in the first 24 hours after the procedure), or restenosis (occurring within the first six months). Recent clinical trials have shown improved outcomes with reduced rates of abrupt closure or clinical restenosis when antiglycoprotein IIb/IIIa, abciximab $^{12}$ (Reo Pro; Eli Lilly), is used in conjunction with standard aspirin and heparin anticoagulation protocols.

This paper reports on a clinical and economic evaluation based on the results of the EPIC trial (the largest phase III trial of abciximab) and long term epidemiological data. Economic evaluation is defined as the comparison of costs and outcomes for two or more interventions. ${ }^{3}$ Consequently, thorough evaluation of the clinical data is pivotal. It is used to quantify the value for money of interventions for decision makers and funders of health care.

The form of economic evaluation used here is cost effectiveness analysis, which uses "natural" or clinical measures of outcome. Value for money is best summarised as a particular ratio: the incremental cost effectiveness ratio. This conveys the additional cost of achieving an additional unit of outcome.

\section{Methods}

\section{CLINICAL EFFECTIVENESS}

The EPIC trial was a prospective, randomised, double blind trial with 2099 patients treated at 56 centres. ${ }^{12}$ Men and women at high risk for ischaemic complications during and after PTCA were randomised to one of three arms: placebo bolus plus placebo infusion for 12 hours (P), $0.25 \mathrm{mg} / \mathrm{kg}$ bolus of abciximab plus placebo infusion for 12 hours (B), or 0.25 $\mathrm{mg} / \mathrm{kg}$ bolus of abciximab plus a $10 \mu \mathrm{g} / \mathrm{min}$ abciximab infusion for 12 hours $(\mathrm{B}+\mathrm{I})$. Standard intravenous heparin and aspirin regimens were given. Approximately $50 \%$ of patients had single vessel disease and $50 \%$ had multivessel disease.

The primary outcome measure was the rate of the following composite events: non-fatal myocardial infarction, death, repeat PTCA/ stent placement, or bypass surgery (hereafter referred to as the event rate). Bleeding events were classified as either major, minor, or insignificant according to the TIMI classification. ${ }^{4}$ 
A combined risk/benefit measure was also derived. Here, the more serious of the clinical or safety events were used.

By the end of the study at six months there was an $8.1 \%$ absolute reduction in events $(95 \%$ confidence interval $3.1 \%$ to $12.7 \%$ ), and a $23 \%$ relative risk reduction $(\mathrm{p}=0.001)$. The most common complication of abciximab was bleeding, although this did not result in a statistically significant increase in serious events. Death due to bleeding was rare and occurred at a similar rate in all groups.

More recent data confirm this level of treatment effect and suggest safer methods of administration. These results enhance the generalisability of the evaluation. A substudy of the EPIC trial $(n=183)$ aimed to assess strategies to reduce the rate of excess bleeding with abciximab and in particular the use of low dose, weight adjusted heparin (PROLOG trial; data on file). It was shown that low dose, weight adjusted heparin in combination with early removal of the arterial sheath appeared to offer the greatest benefit in reducing bleeding complications (to only $1.9 \%$ ). Two other studies have since confirmed the efficacy and safety benefits with heparin adjustment (CAPTURE and EPILOG trials; data on file). Notably, a broad population of patients undergoing PTCA was enrolled in contrast to the high risk category enrolled in the EPIC study. These studies were stopped early because of highly significant reductions in event rates. Both trials used weight adjusted heparin dosage and both found that bleeding was not significantly different from placebo.

\section{COST EFFECTIVENESS}

Two analyses were performed: a cost effectiveness analysis using data from the six month EPIC trial, and an analysis using the results from a model of long term health outcomes. In the former we used event data collected within the EPIC trial for the assessment of costs and outcomes. The outcomes used were the main composite end point, repeat revascularisation, and the combined risk/benefit measure. As is conventional in economic evaluation, outcomes and costs are discounted to reflect a time preference for benefits sooner and costs later. An annual discount rate of $5 \%$ was used. Sensitivity analyses were also performed to assess the robustness of results.

The frequency of clinical events from the trial, both within the initial hospital inpatient episode and beyond, were determined from the full trial dataset. Approximately $40 \%$ of ischaemic events occurred during the initial hospital episode and so only the marginal costs of these events were included. Conversely, events after the initial episode were costed as separate events. Unit costs were mainly derived from the Australian National Casemix costs. ${ }^{5}$

In the case of blood transfusions (generally given for major bleeding), additional costs for critical care and monitoring were included. The cost of blood products was separately determined, given that blood is supplied by donation in Australia and does not have clear unit price. Here, the total costs of the blood collection and distribution service were allocated down to units of blood products.

The average cost per patient was determined by multiplying the frequency of events by associated unit costs. The difference in average costs defines the incremental costs of treatment. Costs are presented in Australian dollars at 1996 prices.

The long term health outcome model served to provide estimates of final end points. Survival, and in single vessel disease only, event-free survival (absence of repeat PTCA, CABG, myocardial infarction, and death), were estimated over a 10 year period. The balance of published epidemiological reports supports improved outcomes with successful PTCA, and so from the modelling perspective the issue is the size of the gain. A Markov process was used, which links the rates of successful and unsuccessful PTCA outcome from the EPIC trial with long term outcome data. ${ }^{6}$

A comprehensive search of the Medline and Embase databases indicated a large body of published studies reporting survival after PTCA. ${ }^{7-31}$ However, few report outcome data according to whether PTCA was clinically successful or unsuccessful or in a form suitable for modelling. Two large cohort studies, one in single vessel disease, ${ }^{12}$ and one in multivessel disease,${ }^{13}$ form the basis of the evidence on long term outcomes. These show that survival, cardiac survival, and event-free survival are improved for those with clinically successful PTCA compared to those with failure.

In single vessel disease $(\mathrm{n}=798)$, successful PTCA is correlated with better overall survival $(\mathrm{p}=0.02)$, cardiac survival $(\mathrm{p}=0.003)$, and event-free survival ( $\mathrm{p}<<0.001$ ). By 10 years the cumulative rate of survival and any event (PTCA, bypass surgery, myocardial infarction, or death) are $92 \%$ v $86 \%$ and $60 \%$ v $15 \%$ for successful and failed PTCA, respectively.

In multivessel disease $(n=637)$, the cumulative rate of cardiac death at five years was $88 \%$ v $77 \%$ for successful and failed PTCA, respectively $(p=0.001)$. One study seems to contradict the survival results and is given due attention in the discussion. ${ }^{17}$

At the end of six months of follow up as described in the EPIC trial, patients enter the model in one of three health states: clinical success (patients free from events); clinical failure (patients who have had an event excluding death); and death, with probabilities taken directly from the EPIC trial. Thereafter, annual transition probabilities based on the annual risks of successful and unsuccessful PTCA were applied from the cohort studies. A simplified schema of the model is presented in fig 1.

The model makes three main assumptions. The first is that the gain in outcomes from successful PTCA in the older cohort studies applies here. This is defended on the basis that the cohort patients have a similar representation of men/women and rates of revascularisation expected in Australia. The second is that improved medical management over time has affected successful and unsuccessful PTCA patients similarly. The third is that patients 

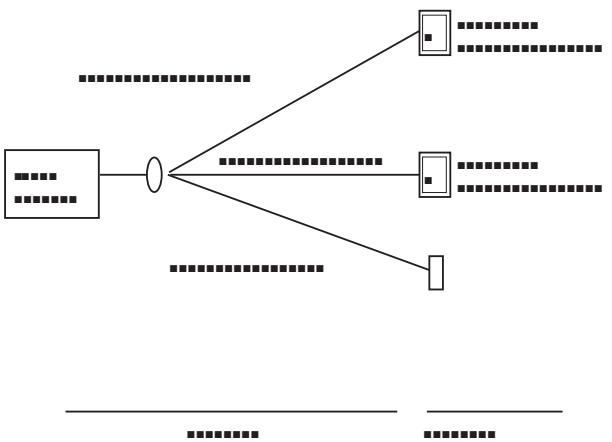

Figure 1 Simplified model. The probabilities of entering the model in the three states are shown for EPIC patients (and placebo patients in brackets). The pivotal aspects of the model are the Markov nodes, labelled " $M$ ". For single vessel disease, survival and event-free times are estimated. For multivessel disease, only survival is estimated. The death branch accounts for the chance of death at the start of the model.

maintaining clinical success by six months in the EPIC trial would enjoy at least the level of benefit shown in patients with immediate success in the cohort studies. This is a conservative assumption because some degree of treatment failure occurs within the first six months after treatment.

The hypothetical patient "inherits" the average costs calculated at the start of the model (that is, at the end of six months and at the start of the Markov process). Many costs are expected to be common for abciximab and placebo patients, such as the use of drugs for coronary heart disease and use of medical services. However, patients who die within the model period or experience a serious event will incur more costs. As these events are more frequent with placebo, this approach will yield results which are conservative.

\section{Results}

EVALUATION OVER SIX MONTHS

Table 1 presents average and incremental costs per patient over six months for placebo and $\mathrm{B}+\mathrm{I}$ regimens. The unit costs are presented in the first column. It can be seen that the average cost per patient for abciximab over the six month trial is $\$ 8019$, versus $\$ 6965$ for placebo.

Table 1 Average and incremental costs (Australian \$) from the EPIC trial

\begin{tabular}{lrrr}
\hline Event & $\begin{array}{c}\text { Average cost, } \\
\text { placebo }\end{array}$ & $\begin{array}{c}\text { Average cost, } \\
\text { abciximab }\end{array}$ & $\begin{array}{c}\text { Incremental } \\
\text { cost }\end{array}$ \\
\hline Single PTCA & 4164 & 4189 & 25 \\
Received abciximab & 0 & 1633 & 1633 \\
CABG during initial hosp & 571 & 466 & -105 \\
Repeat PTCA during hosp & 271 & 156 & -116 \\
Death during initial hosp & 9 & 7 & -2 \\
MI during initial hosp & 57 & 31 & -26 \\
Stent during initial hosp & 22 & 22 & 0 \\
IABP during initial hosp & 133 & 106 & -27 \\
Minor bleeding & 20 & 34 & 14 \\
Transfusions & 65 & 143 & -114 \\
CABG post initial hosp & 623 & 509 & -184 \\
PTCA post initial hosp & 719 & 535 & -16 \\
Death post initial hosp & 118 & 101 & -42 \\
MI post initial hosp & 28 & 21 & -57 \\
CHF post initial hosp & 56 & 14 & $\$ 1054$ \\
Unstable angina post initial hosp & 109 & 52 & \\
Total & & $\$ 8019$ & \\
\hline
\end{tabular}

CABG, coronary artery bypass grafting; CHF, chronic heart failure; hosp, hospital admission; IABP, intra-aortic balloon pump; MI, myocardial infarction; PTCA, percutaneous transluminal coronary angioplasty.
The incremental cost is $\$ 1054$. The $\$ 1640$ cost of abciximab is offset by $\$ 586$ in resource savings which represents one third of its cost.

Table 2 presents the average and incremental cost effectiveness ratios from the trial based evaluation.

It can be seen that the average costs per patient free from a serious event are $\$ 10985$ and $\$ 10732$ for abciximab and placebo, respectively. The higher average cost effectiveness with abciximab is consistent with a drug that provides greater health outcomes at higher cost. For any revascularisation the average cost effectiveness is $\$ 10374$ and $\$ 9865$, respectively. For the risk/benefit measure the average cost effectiveness is $\$ 11231$ and $\$ 10883$, respectively.

The incremental cost effectiveness ratios presented in table 2 indicate the additional cost of additional outcomes. The additional cost per patient free from a serious event is $\$ 13012$. For any revascularisation the additional cost is $\$ 15731$ and for the risk/benefit measure the additional cost is $\$ 14243$.

SURVIVAL MODEL WITH PRELIMINARY ECONOMIC EVALUATION

Table 3 presents the results of the life-year estimates and preliminary economic ratios. $\mathrm{Pa}-$ tients with single vessel disease are estimated to live an extra 0.12 years. Patients with multivessel disease are estimated to live an extra 0.25 years. Given the 50:50 split in the EPIC trial, the typical EPIC patient would be expected to live an extra 0.19 years. The incremental cost per additional life-year gain is estimated at between $\$ 5547$ and $\$ 8783$.

Table 4 presents the results of the event-free year estimates and economic ratio. Patients receiving abciximab are expected to live an extra 0.246 years free from ischaemic events. The cost per additional year of life free of ischaemic events is estimated as $\$ 4285$.

\section{SENSITIVITY ANALYSIS}

Some of the sensitivity analyses are reported here. These involve significant alterations intended to convey the robustness of results to the data sources used. For the trial based evaluation, the incremental ratios were recalculated using event rates based on the upper and lower limits of the $95 \%$ confidence intervals. The incremental ratio for the composite end point ranges between $\$ 11085$ and $\$ 43667$. For the risk-benefit measure, the incremental ratio ranges between $\$ 12001$ and $\$ 60042$. As the composite end point measure was estimated more precisely, the low and high ratios are closer to the base case estimate.

Two sensitivity analyses for the model are reported here:

(1) Eliminating the survival benefit for single vessel disease patients-These patients appear to benefit less than multivessel disease patients. Attributing only the benefit to multivessel disease patients serves as a sensitivity analysis for the modelled evaluation. This increased the incremental ratio by approximately two thirds, with a cost per additional life-year gained of $\$ 8432$. 
Table 2 Average and incremental cost effectiveness ratios from EPIC trial (Australian \$)

\begin{tabular}{|c|c|c|c|c|c|c|c|c|c|}
\hline & \multicolumn{3}{|l|}{ Abcixmab } & \multicolumn{3}{|l|}{ Placebo } & \multicolumn{3}{|c|}{ Incremental analysis } \\
\hline & Avg cost & Effect & $\operatorname{Avg} C / E$ & Avg cost & Effect & $\operatorname{Avg} C / E$ & Incr cost & Incr effect & Incr $C / E$ \\
\hline Composite end point & $\$ 8019$ & 0.73 & $\$ 10985$ & $\$ 6965$ & 0.649 & $\$ 10732$ & $\$ 1054$ & 0.081 & $\$ 13012$ \\
\hline Any revascularisation & $\$ 8019$ & 0.773 & $\$ 10374$ & $\$ 6965$ & 0.706 & $\$ 9865$ & $\$ 1054$ & 0.067 & $\$ 15731$ \\
\hline Risk/benefit measure & $\$ 8019$ & 0.714 & $\$ 11231$ & $\$ 6965$ & 0.64 & $\$ 10883$ & $\$ 1054$ & 0.074 & $\$ 14243$ \\
\hline
\end{tabular}

Avg, average; C/E, cost effectiveness; Effect, effectiveness; Incr, incremental. The effectiveness measures represents the chance of being free from events.

Table 3 Average and incremental cost per life-year ratios from the EPIC trial (Australian \$)

\begin{tabular}{|c|c|c|c|c|c|c|c|c|c|}
\hline & \multicolumn{3}{|c|}{ Abciximab } & \multicolumn{3}{|l|}{ Placebo } & \multicolumn{3}{|c|}{ Incremental analysis } \\
\hline & Avg cost & Life-years & $\begin{array}{l}\text { Avg cost/ } \\
\text { life-year }\end{array}$ & Avg cost & Life-years & $\begin{array}{l}\text { Avg cost/ } \\
\text { life-year }\end{array}$ & Incr cost & $\begin{array}{l}\text { Incr } \\
\text { life-years }\end{array}$ & $\begin{array}{l}\text { Incr cost } \\
\text { life-year }\end{array}$ \\
\hline $\begin{array}{l}\text { All EPIC patients } \\
\text { Single vessel }\end{array}$ & $\$ 8019$ & 6.67 & $\$ 1202$ & $\$ 6965$ & 6.48 & $\$ 1075$ & $\$ 1054$ & 0.19 & $\$ 5547$ \\
\hline $\begin{array}{l}\text { disease } \\
\text { Multivessel }\end{array}$ & $\$ 8019$ & 7.45 & $\$ 1076$ & $\$ 6965$ & 7.33 & $\$ 950$ & $\$ 1054$ & 0.12 & $\$ 8783$ \\
\hline disease & $\$ 8019$ & 5.88 & $\$ 1364$ & $\$ 6965$ & 5.63 & $\$ 1237$ & $\$ 1054$ & 0.25 & $\$ 4216$ \\
\hline
\end{tabular}

Avg, average; Incr, incremental.

Table 4 Average and incremental cost per event-free year ratios from EPIC trial (single vessel disease only) (Australian \$)

\begin{tabular}{|c|c|c|c|c|c|c|c|c|c|}
\hline & \multicolumn{3}{|c|}{ Abciximab } & \multicolumn{3}{|l|}{ Placebo } & \multicolumn{3}{|c|}{ Incremental analysis } \\
\hline & Avg cost & Years free & $\begin{array}{l}\text { Avg cost/ } \\
\text { years free }\end{array}$ & Avg cost & $\begin{array}{l}\text { Years } \\
\text { free }\end{array}$ & $\begin{array}{l}\text { Avg cost/ } \\
\text { years free }\end{array}$ & $\begin{array}{l}\text { Incr } \\
\text { cost }\end{array}$ & $\begin{array}{l}\text { Incr years } \\
\text { free }\end{array}$ & $\begin{array}{l}\text { Incr cost/ } \\
\text { year free }\end{array}$ \\
\hline $\begin{array}{l}\text { Single vessel } \\
\text { disease }\end{array}$ & $\$ 8019$ & 3.079 & $\$ 2604$ & $\$ 6965$ & 2.833 & $\$ 2459$ & $\$ 1054$ & 0.246 & $\$ 4285$ \\
\hline
\end{tabular}

Avg, average; Incr, incremental.

(2) Halving the number of event-free years gained-Freedom from cardiac events was substantially lower with successful PTCA. Halving the number of event-free years gained increased the incremental ratio to $\$ 11715$.

\section{Discussion}

A clinical and economic evaluation of the addition of abciximab to heparin plus aspirin anticoagulation in candidates at high risk for PTCA has been presented. The approach has been first, to assess the results from all randomised trials and second, to extrapolate long term outcomes supported by good quality epidemiological data.

Given the high cost of abciximab compared to the standard anticoagulation regimen with PTCA, the value for money analysis of treatment is clearly important. In essence, abciximab represents a one off additional cost to PTCA which is offset by one third in savings (mainly in reduced need for revascularisation).

Balanced against this cost are improved intermediate and potential long term outcomes with abciximab. Over six months, there is an $8.1 \%$ absolute risk reduction in serious cardiovascular events. This translates into a number "needed to treat" of 12 to 13 patients to obtain this benefit.

The additional rate of major bleeding $(7 \%)$ is clearly of some concern to practitioners. However, no death from haemorrhage was caused by abciximab and no difference in the rate of stroke or cerebral haemorrhage. As a result, the long term consequences of bleeding events are not expected to be significant. The PROLOG, EPILOG, and CAPTURE trials indicate that weight adjustment of heparin with timely sheath removal (four to six hours after heparin) has largely eliminated the excess risk of major bleeding.

The generalisability of these trials appears good, given that they are unlikely to be harbouring important biases in view of their size and double blinded design. Procedures were performed in a standard manner and results were analysed on an "intention to treat" basis including all randomised patients, which enables the results to be applied to the clinical setting. Further, the CAPTURE and EPILOG studies provide indications that similar or greater treatment benefit exists in a broader patient population such as patients scheduled for elective PTCA with unstable angina.

Long term outcomes were modelled to provide estimates for final end points. The balance of long term follow up studies supports improved survival and event-free survival with successful PTCA and highlights multivessel disease as a serious risk factor. One important study by Weintraub et al seems to contradict the relation between restenosis and higher risk of mortality but supports the event-free survival estimates. ${ }^{17}$ This well conducted study assessed 3363 patients undergoing angiographic restudy four months to one year after PTCA. At six years, there was only a trend to better survival rates-95\% v 93\% for no restenosis and restenosis, respectively $(\mathrm{p}=0.16)$.

There were statistically significant reductions in the incidences of myocardial infarction, repeat PTCA, and repeat CABG. Restenosis was found to be an independent correlate of these events, but not mortality. Interestingly, repeat revascularisation was the 
most common event for those with restenosis, and examination of the rates of repeat PTCA is revealing. Seventy five per cent of patients with restenosis had repeat PTCA within 12 months. This compares with a rate of $22 \%$ in Australia. ${ }^{32}$ The rate of revascularisation in the two American cohort studies was approximately $25 \%$ at one year, indicating better applicability to the Australian setting. Repeat PTCA was not examined for its independent effect on survival in the Weintraub study and the authors point to the possibility that the high rate of revascularisation may have led to their results for survival.

LIMITATIONS OF THE STUDY

Potential limitations of this study are acknowledged. First, the Weintraub study places some doubt as to the gain in survival from successful PTCA but confirms this study's conclusions on better event-free survival (particularly less revascularisation after restenosis).

Second, the incremental costs estimated relate only to the first six months of treatment. There is a possibility that additional costs will become evident, perhaps due to the management of those who live longer. Offsetting this are the likely lower costs from less repeat PTCA and bypass surgery.

Third, these results are most applicable to the high risk patients as defined in the EPIC trial, but not necessarily to all PTCA candidates. However, the early results of treatment in a broader patient group are encouraging at this stage. The CAPTURE study includes an angiographic substudy of 1000 patients, the results of which will better address the generalisability of treatment effect to the wider PTCA population.

Fourth, the usefulness of treatment alongside the use of coronary stents is also unclear. Stenting is becoming a more common feature of clinical intervention and this may increasingly limit the generalisability of our results. A stent substudy of the EPILOG trial and two planned studies (STEREO 1 and STEREO 2 trials; in press) will address this treatment question. As PTCA without stenting is still common practice, the results are currently of clinical interest.

It is important that value for money is explored early on in the adoption of a new technology. Funders and decision makers can decide on whether the economic ratios presented are attractive value for money. These results can be applied to other health care systems where their acquisition costs of abciximab are similar as this represents the pivotal cost index.

\section{CONCLUSION}

In conclusion, abciximab has been shown to reduce the rate of restenosis substantially in patients at high risk for PTCA. Indications are that the same level of benefit may be expected in non-high risk elective PTCA. With appropriate regimens, the rate of major bleeding is only marginally above that of placebo and has not resulted in excess stroke or other serious haemorrhage. Survival extension with freedom from morbidity is supported by published epidemiological reports. The one-off cost of abciximab offers short term improvements in clinically important outcomes. This study also explores and highlights the likelihood of significant long term health benefits.

This study was funded by Eli Lilly Australia Pty Ltd.

1 Topol EJ, Califf RM, Weisman HF, Ellis SG, Tcheng JE, Worley S, et al. Randomised trial of coronary intervention with antibody against IIb/IIIa integrin for reduction of clinical restenosis: results at six months. Lancet 1994;343:881-5.

2 Califf RM, the EPIC Investigators. Use of a monoclonal antibody directed against the platelet glycoprotein IIb/IIIa receptor in high-risk coronary angioplasty. $N$ Engl f Med 1994;330:956-61.

3 Drummond MF, Stoddart GL, Torrance GW. Methods for the economic evaluation of health care programmes. Oxford: Oxford University Press, 1987:48-53.

4 Rao AK, Pratt C, Berke A, Jaffe A, Ockene I, Schreiber TL, et al. Thrombolysis in Myocardial Infarction (TIMI) Trial-phase I: haemorrhagic manifestations and changes in plasma fibrinogen and the fibrinolytic system in patients in plasma fibrinogen and the fibrinolytic system in patients treated with recombinant tissue plasminogen activ
streptokinase. $₹$ Am Coll Cardiol 1988;11:1-11.

5 Commonwealth of Australia. Manual of resource items and their associated costs: for use in submissions to the Pharmaceutical Benefits Advisory Committee involving economic analysis. Canberra: Department of Health, Housing, Local Government and Community Services, 1993.

6 Sonnenberg FA, Beck J. Markov models in medical decision making: a practical guide. Med Decis Making 1993;13:32288.

7 De Feyter PJ, Suryapranata H, Serruys PW, Beatt K, Van Domburg R, Van Den Brand $M$, et al. Coronary angioplasty for unstable angina: immediate and late results in 200 consecutive patients with identification of risk factors for unfavorable early and late outcome. $7 \mathrm{Am}$ Coll Cardiol 1988;12:324-33.

8 Frierson JH, Dimas AP, Whitlow PL, Hollman JL, Marsalese DL, Simpfendorfer CC, et al. Angioplasty of the proximal left anterior descending coronary artery: initial proximal left anterior descending coronary artery: initial 1992;10:745-51.

9 Mick MJ, Piedmonte MR, Arnold AM, Simpfendorfer C. Risk stratification for long-term outcome after elective coronary angioplasty: a multivariate analysis of 5,000 patients. F Am Coll Cardiol 1994;24:74-80.

10 Webb JG, Myler RK, Shaw RE, Anwar A, Murphy MC, Mooney JF, et al. Bidirectional crossover and late outcomes after coronary angioplasty and bypass surgery: 8 to 11 year follow-Up. 7 Am Coll Cardiol 1990;16:57-65.

11 Weintraub WS, Wenger NK, Kosinski AS, Douglas JS, Liberman HA, Morris DC, et al. Percutaneous transluminal coronary angioplasty in women compared with men. $\mathcal{F}$ Am Coll Cardiol 1994;24:81-90.

12 Kadel C, Vallbracht C, Buss F, Kober G, Kaltenbach M. Long-term follow-up after percutaneous transluminal cong-term follow-up after percutaneous transluminal Am Heart 7 1992;124:1159-69.

13 Vandormael M, Deligonul U, Taussig S, Kern MJ. Predictors of long-term cardiac survival in patients with multivessel coronary artery disease undergoing percutaneous transluminal coronary angioplasty. Am f Cardiol 1991; 67:1-6.

14 Brodie BR, Stuckey TD, Hansen CJ, Cooper TR, Weintraub $\mathrm{RA}$, LeBauer EJ, et al. Importance of a patent infarctrelated artery for hospital and late survival after direct coronary angioplasty for acute myocardial infarction. $\mathrm{Am} \mathcal{F}$ Cardiol 1992;69:1113-9.

15 Sahni R, Maniet AR, Banka VS. Long-term efficacy of percutaneous transluminal angioplasty on incidence of myocardial infarction, relief of symptoms and survival. Clin Cardiol 1989;12:427-31.

16 Weintraub WS, Ghazzal ZMB, Cohen CL, Douglas JS, Liberman H, Morris DC, et al. Clinical implications of late proven patency after successful coronary angioplasty. proven patency after succes
Circulation 1991;84:572-82.

17 Weintraub WS, Ghazzal ZMB, Douglas JS, Liberman HA, Morris DC, Cohen CL, et al. Long-term clinical follow-up in patients with angiographic restudy after successful angioplasty. Circulation 1993;87:831-40.

18 O'Murchu B, Gersh BJ, Reeder GS, Bailey KR, Holmes DR. Late outcome after percutaneous transluminal coronary angioplasty during acute myocardial infarction. Am f Cardiol 1993;72:634-9.

19 Wilson SW, Stone GW. Late results of percutaneous transluminal coronary angioplasty of two or more major native coronary arteries. Am f Cardiol 1994;73:1041-6.

20 Hochberg MS, Gielchinsky I, Parsonnet V, Hussain SM, Mirsky E, Fisch D. Coronary angioplasty versus coronary bypass. F Thorac Cardiovasc Surg 1989;97:496-503.

21 Akins CW, Block PC, Palacios IF, Gold HK, Carroll DL, Grunkemeier GL. Comparison of coronary artery bypass grafting and percutaneous transluminal coronary angioplasty as initial treatment strategies. Soc Thorac Surg oplasty as initial 
22 Gruentzig AR, King SB, Schlumpf M, Siegenthaler W. Long-term follow-up after percutaneous transluminal
coronary angioplasty. $N$ Engl f Med 1987;316:1127-32.

23 Kramer JR, Proudfit WL, Loop FD, Goormastic $M$ Zimmerman K, Simpfendorfer C, et al. Late follow-up of 781 patients undergoing percutaneous transluminal coronary angioplasty or coronary angioplasty or coronary artery bypass grafting for an isolated obstruction in the left anterior descending coronary artery. Clin Invest 1989;118 1144-53.

24 Bourassa MG, Wilson JW, Detre KM, Kelsey SF, Robertson T, Passamani ER, et al. Long-term follow-up of coronary angioplasty: the 1977-1981 National Heart, Lung \& Blood Institute registry. Eur Heart f 1989;10(suppl G):36-41.

25 Bell MR, Bailey KR, Reeder GS, Lapeyre AC, Holmes DR. Percutaneous transluminal angioplasty in patients with multivessel coronary disease: how important is complete (1) Cardiol 1990;16:553-62.

26 King SP. Coronary angioplasty: long-term survival com pared with coronary bypass surgery. Transactions of the Association of Insurance Medical Directory of America New Association of Insurance
York) 1989;72:88-94.

27 Stach RS, Califf RM, Hinohara T, Phillips HR, Pryor DB, Simonton CA, et al. Survival and cardiac event rates in the first year after emergency coronary angioplasty for acute myocardial infarction. I Am Coll Cardiol 1988;11:1141-9.

28 Detre K, Yeh W, Kelsey S, Williams D, Desvigne NP, Holmes D, et al. Has improvement in PTCA intervention affected long-term prognosis? The NHLBI PTCA registry experience. Circulation 1995; 91:2868-75.

29 Reynen K, Kunkel B, Bachmann K, Gansser R, Martus P. PTCA in elderly patients: acute results and long-term follow-up. Eur Heart f 1993;14:1661-8.

30 Nobuyoshi M, Nosaka H. Initial success rate and complications of elective PTCA in 5064 patients. Fpn Circ $\mathcal{f}$ 1991;55:804-8.

31 King SB. PTCA — clinical aspects. $Z$ Kardiol 1987;76:1-4. 2 National Heart Foundation (Australia). Report on coronary angioplasty. Report No 9; August, 1995. 